\title{
Effect of structured physical exercise program on older adult's daily living activities and cognitive functions
}

\author{
Manal Hassan Abo El-Magd ${ }^{1 *}$, Sahar Mahmoud Zaki ${ }^{2}$ \\ ${ }^{I}$ Assistant Professor of Psychiatric and Mental Health Nursing, Faculty of Nursing, El-Minia University, Egypt \\ 2 Lecturer of Community Health Nursing, Faculty of Nursing, Cairo University, Egypt \\ *Corresponding author E-mail: manalh225@gmail.com
}

\begin{abstract}
Background: Older adults experience marked physiological and cognitive changes. Literature states that, daily exercising positively effects older adults' both physical and cognitive functioning. Aim: To evaluate the effect of the developed Structured Physical Exercise Program (SPEP) on both older adult's activities of daily living and cognitive functions. Subjects and methods: A quasi experimental design (pre/ post- tests) was utilized for the current study where the older adults' sample served as their own control. The study was conducted at a charity geriatric home (Female section) in Giza Governorate on a convenient sample of 45 older adult females. Data were collected through using three tools; Personal and clinical data assessment sheet, and the two pre-post scales (i.e. Activity of Daily Living scale "ADL" and Nurses' Observation Scale for Cognitive Abilities "NOSCA"); both scales were already developed and tested before. Results: Data revealed that, after implementation of SPEP, statistically significant differences, indicating improvement, were found between the older adult's ADL and both their age, presence of support network, the number of offspring and medical history. Also Statistically significant difference, indicating improvement, was found between ADL and NOSCA scales among the study sample before and after implementing the SPEP. Conclusion: Both ADL level and cognitive functions of study sample were significantly improved after implementing the SPEP. Regular physical exercising is likely to have positive effect on both older adults' physical and cognitive functioning resulting in higher level of independency. Recommendation: This study recommends wide range application of the developed SPEP on older adults in Egypt.
\end{abstract}

Keywords: Activities of Daily Living (ADL); Cognitive Function; Nurses' Observation Scale for Cognitive Abilities (NOSCA); Older Adult; Structured Physical Exercise Program (SPEP).

\section{Introduction}

It is believed that, "the ageing process is a biological reality which has its own dynamic, largely beyond human control. However, it is also subject to the constructions by which each society makes sense of old age. In the developed world, chronological time plays a supreme role. The age of 60 or 65 , roughly equivalent to retirement ages in most developed countries is said to be the beginning of old age (Heyn et al 2004). Actually, in contrast to the chronological milestones which mark life stages in the developed world, old age in many developing countries is seen to begin at the point when active contribution is no longer possible" (Graf 2008).

Stereotypes about aging are often inaccurate. In developed countries, most of older adults live independently and maintain close relationships with family and friends; meanwhile, this may not be the case in developing countries (WHO 2013). Depression among institutionalized older adults is less prevalent than depression in younger adults. However, older adults do experience normal agerelated changes that may affect their lifestyle (American psychological association APA item 2 \& item 3 2013). Common agerelated physical changes include hearing impairment, weakening vision, and the increasing probability of arthritis, hypertension, heart disease, diabetes, and osteoporosis (APA item 3 \& item 6 2013).
Regarding cognitive functioning, the speed with which information is encoded, stored, and received may decrease with aging (APA item 3 \& item 6 2013). The rapidity of the decline in function varies with the organ system under consideration but is relatively constant within a given system. Thus, the rate of aging remains the same until the age of 85 where more age related changes have been accumulated (Woodford \& George 2007).

Cognitive dysfunction is a deterioration of intellectual functions such as thinking, remembering, and reasoning of sufficient severity to interfere with daily functioning. Patients with cognitive dysfunction have trouble with verbal recall, basic arithmetic, and concentration (Suzuki et al 2012).

An important concept is the distinction that must be made between the normal attrition of function occurring in all persons with advancing age and the loss of function that marks the onset of pathological changes from one or more of the diseases encountered with increased prevalence in the older age group. Failure to recognize this difference can lead to progressive disability from treatable diseases in many cases (Wiener, Joshua et al 2013).

Regular moderate intensity physical activity such as walking, cycling, or participating in sports has significant benefits for health (Wiener, Joshua et al 2013). For instance, it can reduce the risk of cardiovascular diseases, diabetes, colon and breast cancer, and depression. Moreover adequate level of physical activity will 
decrease the risk of a hip or vertebral fracture and help control weight (WHO May 2013).

It is believed that, exercise has multiple positive effects in older adults, including those with disabilities. More precisely, exercise prevents and reduces the risk of developing secondary conditions that arise from functional decline and physical inactivity. Regular exercise that focuses on functional fitness, such as walking, has been associated with significant reductions in the levels of dependence and disability in older adults (WHO May 2013 \& Kovatch et al 2013).

In addition to improved feelings of physical and mental wellbeing, exercise can provide a number of additional benefits to the elderly. Exercise can help you maintain physical strength and flexibility, improve the range of motion and increase your energy levels. Exercise may also help specific health conditions, like high blood pressure, heart disease, diabetes and balance problems (Kovatch \& Segal 2013).

Regular physical activity and exercise is the key to remain at the optimum level of older adult's health, which is of incredible importance both to physical and mental health of almost everyone. It can help manage stress and improve individuals' mood. Also it can help to prevent or delay many diseases and disabilities. In some cases, exercise is an effective treatment for many chronic conditions. Even a minimal exercise may protect the elderly from longterm memory loss and even help reverse some of the effects of aging (Kamegaya, et al. 2012).

\section{Significance of study}

Regular physical exercise is considered the key for older adults to remain at the optimum level of health due to its ultimate importance to both older adults' physical and mental health. This is simply because, regular physical exercise can help prevent or delay many physical diseases and disabilities of older adults as well as help managing their stress and improving their mood (Kamegaya, et al. 2012). In some cases, regular physical exercise would protect the older adults from long-term memory loss and even help reverse some of the cognitive effects of aging. All of these aspects would inevitably improve the older adults' performance of their daily living activities.

\section{Aim of study was two fold}

1) To assess daily living activities and cognitive functions of older adults.

2) To evaluate the effect of the developed structured physical exercise program on both older adult's activities of daily living and cognitive functions.

\subsection{Subjects and methods}

\section{Research hypotheses}

1) Performance of daily living activities among older adults will be improved after the implementation of the structured physical exercise program.

2) Cognitive function of the older adults will be improved after the implementation of the structured physical exercise program.

\section{Research design}

A quasi experimental deign (pre/ post- tests) was utilized in the current study where the older adults' sample served as their own control. Such design fits the nature of the problem under investigation and is frequently used in nursing researches.

\section{Sample size and characteristics}

A convenient sample of 45 out of the total 60 older adult females was enrolled to the study according to the following inclusion and exclusion criteria.

\section{Inclusion criteria}

- Older adults aged 60 years or more.

- Only female older adult.
- Older adults whom physical and physiological health status allows them to participate in the program (as apprised by the geriatric home resident physician).

- Exclusion Criteria:

- Chronic disease hindering participation in physical exercise (decided by the older adults' responsible / resident physicians).

- Comatose clients.

\section{Setting}

The current study was conducted at a charity geriatric home (Female section) in Giza Governorate. This geriatric home is of convenient area and location as well. It consists of seven floors; three of them are dedicated to females. Generally, it's hygienic with moderate density older adults' rooms. Convenient medical and nursing staffs are available.

\section{Tools of data collection}

Data were collected through using three tools, one of them was constructed by the researchers which is the personal and clinical data assessment sheet; while the other two tools were already established, tested and used before which are Katz Index of Independence in Activities of Daily Living (ADL) (Mary \& Meredith 1970) and Nurses' Observation Scale for Cognitive Abilities (NOSCA) (Persoon etal 2003).

1) Personal and clinical data assessment sheet.

An interview questionnaire sheet was developed by the researchers covering the following items: age, length of stay in the geriatric home, main physical complains presence of support network and medical diagnosis (es).

2) Katz Index of Independence in Activities of Daily Living (ADL)

\section{It composed of six criteria, they are}

Bathing: includes grooming activities such as shaving, and brushing teeth and hair.

Dressing: choosing appropriate garments and being able to dress and undress, having no trouble with buttons, zippers or other fasteners.

Eating: being able to feed one

Transferring: being able to walk, or, if not ambulatory, being able to transfer oneself from bed to wheelchair and back.

Continence: being able to control one's bowels and bladder, or manage one's incontinence independently.

Toileting: being able to use the toilet.

Total score was 6. A total score was classified into three levels; a score of "6" indicates full function,"4" indicates moderate impairment and 2 or less indicates severe functional impairment.

Validity and Reliability of Katz Index of Independence in Activities of Daily Living (ADL): In the forty-eight years since the instrument has been developed, it has been modified and simplified and different approaches to scoring have been used. However, it has consistently demonstrated its utility in evaluating functional status in the elderly population. Although no formal reliability and validity reports could be found in the literature, the tool is used extensively as an assessment standard of functional capabilities of older adults in clinical and home environments (Best practice information on care of older adults 2012).

3) Nurses' Observation Scale for Cognitive Abilities (NOSCA) It is a widely used test for cognitive function among the elderly; it includes the following five items:

Orientation: Person's awareness of self with regard to position, time, place and personal relationships.

Attention: Person's ability to concentrate on one thing despite other things going on around him.

Memory: Person's ability to hold information in mind for a brief period of time to perform some task. 
Language: Verbal abilities including vocabulary are preserved with age. Common changes have to do with word retrieval or the process of getting words out.

Visual-spatial skills: Pertaining to the perception of the spatial relationships between objects in one's field of vision; also called visuo-spatial.

The total score ranges from 0 to 24 . The subjects' response of "3" means that no problems were observed; "2"means that problems sometimes arose; "1" means that problems usually arose and "0" means that problems arose repeatedly.

Norm value of the NOSCA overall scale: lower scores indicate less cognitive abilities. 24 means no cognitive problems were observed while 0,0 means cognitive problems arose repeatedly.

Validity and reliability of the total Nurses' Observation Scale for Cognitive Abilities (NOSCA): Use of the (NOSCA) yields standardized, reliable and valid information about patient's cognitive behaviour in daily practice. Cronbach's $\alpha$ of the (NOSCA) and its subscales was $0 \bullet 98$ and $0 \bullet 66-0 \bullet 93$, respectively. The item-total correlations were satisfactory (overall $>0 \bullet 4$ ) (Persoon et al 2012). The structured physical exercise program:

It has been developed by the researchers after extensive review of the relevant literature, and the available resources. The researchers were guided by literature guidelines particularly by centers for disease control and prevention (CDC 2002) guidelines \& Kovatch etal (2013),

The general objectives of the structured physical exercise program (SPEP) were 1) To educate the older adults in the study sample about ways to achieve an active life style, 2) To help older adults maintain healthy bones, muscles and joints, 3) To improve the older adults' activities of daily living and cognitive functions.

\section{The study was conducted through the following phases}

\section{1) Preparatory phase:}

A review of the related literature covering all aspects of the study; available books, journals articles and magazines was done to get acquainted with the research problem and develop the study tool and guided the researchers in tool preparation process used in the study. Through the assessment phase, data collection tools and media were prepared by the researchers in the form of booklet. It took about three months, beginning on 8 May 2013 to 21 August 2013.

2) Planning Phase (Preparatory Phase)

Planning phase includes the program strategy time, number of sessions, teaching methods, media used and the teaching place. This program consists of 10 sessions.

In the beginning of every session, there was brief information about the importance and the effect of the exercises on the body systems. Every session had a warm up and cool down exercises as the basic and two changeable workout, every session lasted about 45 minutes, the knowledge 10 minutes, warm up 10 minutes, the main workout 20 minutes, the cool down 5 minutes .

3) Implementation of the structured physical exercise (Implementation Phase):

At the beginning a written approval was taken from the director of the charity geriatric home (Female section) in Giza Governorate after explaining the strategy of the study. Then the study aim was explained to the female older adults and their consents were obtained to participate in the research.

The study sample $(n=45)$ were classified randomly into 6 groups. Each group was consisted of 7 to 8 members. Each two groups applied the program sessions in a parallel way within the same week on different days. The total numbers of program sessions were 10, one session /week for each group. Pre-test was done in the first session before implementation of the program for al groups. The time required for completing the questionnaire sheet was about 15 minutes for each client. The total time used in program application was 10 weeks beginning in 22-8-2013 to 3-11 2013.

Session 1; "Pre-test and introduction about the program".
Session 2; Practice for breathing exercises no more than 4 or 5 at time, Knee extension, Heel Raises, Arm abduction, arms up and cross arms.

Session 3: Seated in a chair with good posture hold a ball with both hands slightly in front of the body Squeeze the ball to activate the finger joints, then slowly press the ball with both hands, as if trying to deflate the ball. Hold for 4 seconds and slowly release.

Session 4: Ball chest exercise, starting with the ball middle toward the chest by keeping shoulders back at all times squeezing the ball slightly as you push the ball away. Taking about 2 seconds to extend the arms then, squeeze shoulder blades together and pull the ball back toward chest.

Session 5: Tummy twists, holding a ball with both hands and slowly rotate hand to the right as far as comfortable then, rotate back to the center and repeat in the opposite direction. Knee extensions, sitting toward the edge of a chair with good posture and bent knees, hold on to the sides of the chair with your hands .Extend the right knee out being sure to keep the knee slightly bent Lower the leg back to a bent position and repeat this using about 2 seconds each to lift and lower the leg.

Session 6: Overhead arm extensions, seated in a chair with good posture, hold a ball with both hands and raise it up over head, with arms extended without locking the elbows. Keeping the elbows pulled in toward the head, slowly bend the elbows to lower the ball down along the back of the neck, using about 2 seconds to go down, and then 2 seconds to push the ball back up over your head. Heel Raises Seated toward the edge of a chair with good posture and knees bent, place feet flat on the floor Raise heels up off the floor, coming up onto the balls of the feet. Hold for 1 second, then release.

Session 7: Overhead Reach with Side Bends

Seated in a chair with good posture, reach arms up overhead. Hold for 10 seconds. Allow your right arm to relax down by your side (can rest hand on chair seat while your left arm stays up overhead) Slowly lean to the right and reach left arm over your head to the right. Hold for 8 to 10 seconds. Come back up to the center position, pulling both arms overhead again. Repeat by bending to the opposite side relaxing the left arm to the side this time.

Neck Stretch Seated in a chair with good posture; slowly tilt head toward right shoulder. Hold the head in this position, and extend left arm out to the side and slightly downward so that hand is at waist level. Release and repeat on the left side.

Session 8: Forearm: Supination - turn lower hand so palm is up Pronation - turn lower hand so palm is down .Wrist , Fingers \& thumb Flexion - bend wrist forward ,Hyperextension - bring dorsal surface of hand as far back as possible, Abduction (radial flexion) - bring wrist medially towards the thumb ,Adduction (ulnar flexion) - bend wrist laterally towards 5 th finger

Fingers \& thumb: Flexion - bend fingers \& thumb into palm make a fist Extension - straighten fingers \& thumb, Hyperextension bend fingers as far back as possible, Abduction - spread fingers apart / extend thumb laterally Adduction - bring fingers together/ thumb

Session 9; Shoulder and Elbow exercises (are there mention before)

Session 10: Evaluation of the physical exercise session by conducting the post- test.

All of the older adults in the study sample had completed the whole structured physical exercise program sessions

\section{Ethical consideration}

All the relevant ethical principles in research were followed. The study protocol was approved by the pertinent authority. Participants' oral informed consent to participate was obtained after informing them about the program objectives and benefits as well as their rights to participate, refuse, or withdraw at any time. Total confidentiality of any obtained information was ensured. The study maneuver was considered to be safe for participants. How- 
ever, the program is provided in a facility where medical assistance could be easily accessed if any problems arose.

\section{A pilot study}

A pilot study was conducted at the beginning of the study. It included 5 older adults to investigate the feasibility of data collection tools and their clarity and they were included in the study sample later.

\section{Statistical analysis:}

Data entry and statistical analysis were done using SPSS 16.0 statistical software package. Data were presented using descriptive statistics and Chi- square test was used to measure the differences between pre- test and post- test for nonparametric variables and Ttest for parametric variables. Pearson correlation analysis was used for assessment of the inter-relationships among quantitative variables. Statistical significance was considered at $p$-value $<0.05$.The entire document should be in Times New Roman. The font sizes to be used are specified in Table 1 .

\section{Results}

Table (1) shows that, the majority of the sample (80\%) aged more than 70 years while a minority of $6.7 \%$ aged $65-70$ Years. Regarding presence of support network data revealed that, the majority of the study sample $(75.5 \%)$ had support network. Also data revealed that, about one third (33.3\%) of the study sample have 1-2 offspring compared to $60 \%$ who have 3-5 offspring.

Figure (1) illustrates that, more than half of the study sample $(53.3 \%)$ stayed more than three years at the geriatric home in contrast with $40 \%$ who had less than one year of stay there.

Table (2) depicts that, more than half of the study sample (53.3\%) had a medical history of DM and $40 \%$ had a medical history of hypertension compared to $6.7 \%$ of the study sample had a medical history of breast cancer. Concerning main complain, data showed that, more than half of the study sample $(53.3 \%)$ had a main complaint of joint stiffness compared to one fifth of the study sample (20\%) who had a main complaint of urinary tract infection and another one fifth $(22.22 \%)$ had a main complain of back pain. Meanwhile, around one sixth $(15.55 \%)$ of the study sample had a main complaint of sleep disturbance.

Figure (2) depicts that, more than half of the study sample (53.3\%) were completely dependent before implementing the structured physical exercise program compared to $46,6 \%$ being completely dependent after implementing / participating in the program While more than a quarter of the study sample (26.7\%) were independent before implementing the structured physical exercise program compared to $33.3 \%$ became independent after implementing /participating in the program.

Table (3) shows that, statistically significant difference was found between level of performing ADL and study sample's different ages $(\mathrm{X} 2=2.500 \& \mathrm{P}$ - value $=0.045)$. Also data revealed that, high statistically significant difference was found between level of performing ADL and the presence of study sample's support network $(\mathrm{X} 2=0.714 \& \mathrm{P}$ - value $=<0.001)$. Moreover, statistically significant difference was found between the study sample's number of offspring and the presence of support network $(\mathrm{X} 2=5.407$ $\& \mathrm{P}$-value $=0.048$ ).

Table (4) shows that, no statistically significant difference was found between the study sample's cognitive level and neither their ages, presence of neither support network nor number of offspring. Table (5) depicts that, statistically significant differences, indicating improvement, were found between all NOSCA scale items before and after applying the structured physical exercise program. Table (6) depicts that, statistically significant differences, indicating improvement, were found between ADL and NOSCA scale scores of older adults before and after applying structured physical exercise program $(\mathrm{P}$ - value $=0.007 \& 0.004)$ respectively.
Table 1: Socio Demographic Characteristics of Older Adults in the Study Sample $(\mathrm{N}=45)$.

\begin{tabular}{lll}
\hline Socio-Demographic Data & NO. & $\%$ \\
\hline 1. Age by years & & \\
$60-65$ & 6 & 13.3 \\
$>65-70$ & 3 & 6.7 \\
$>70$ & 36 & 80.0 \\
2-Presence of support network & & \\
-Present & 34 & 75.5 \\
-Not present & 11 & 24.5 \\
3-Number of offspring & & \\
1-2 & 15 & 33.3 \\
$3-5$ & 27 & 60.0 \\
6 or more & 3 & 6.7 \\
\hline
\end{tabular}

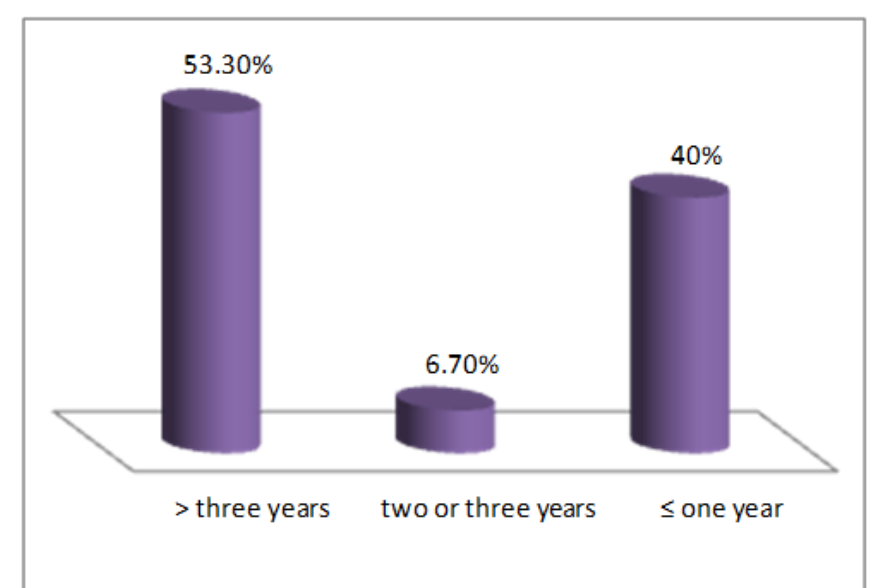

Fig. 1: Length of Older Adults Study Sample's Stay in Geriatric Home (N = $45)$.

Table 2: Percentage Distribution of Older Adults' Medical History in the Study Sample (N = 45)

\begin{tabular}{lll}
\hline Medical History Data & No. & $\%$ \\
\hline Physical disorders & & \\
Diabetes Mellitus (DM) & 24 & 53.3 \\
Hypertension & 18 & 40.0 \\
Rheumatism & 6 & 13.3 \\
Breast Cancer & 3 & 6.7 \\
Psychological disorders & & \\
Dementia & 8 & 17.77 \\
Schizophrenic & 7 & 15.55 \\
Main Complaint (s) & & \\
Urinary Tract Infection & 9 & 20 \\
Sleep Disturbance & 7 & 15.55 \\
Joint Stiffness & 24 & 53.3 \\
Back Pain & 10 & 22.22 \\
\hline
\end{tabular}

Back Pain

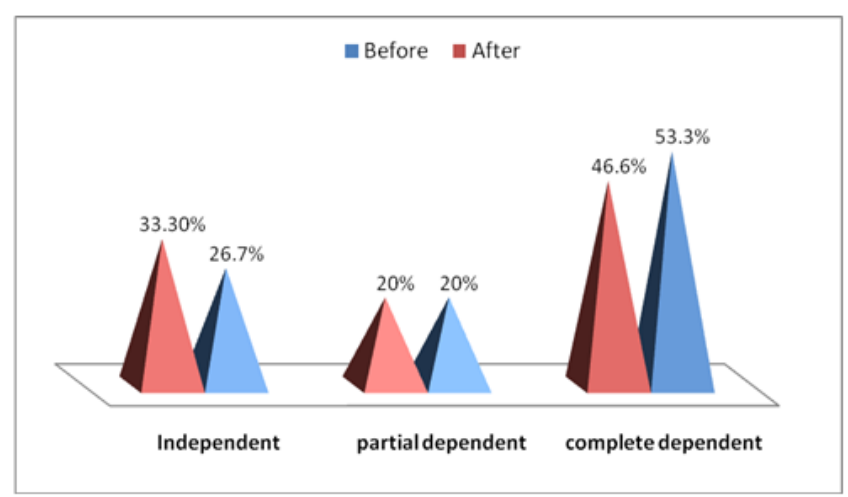

Fig. 2: Activities of Daily Living Performance Levels Before and After Applying the Structured Physical Exercise Program Among of Older Adults' in the Study Sample $(\mathrm{N}=45)$. 
Table 3: Correlation between the Study Sample Older Adults' Activity of Daily Level and Their Socio Demographic Characteristics $(\mathrm{N}=45)$

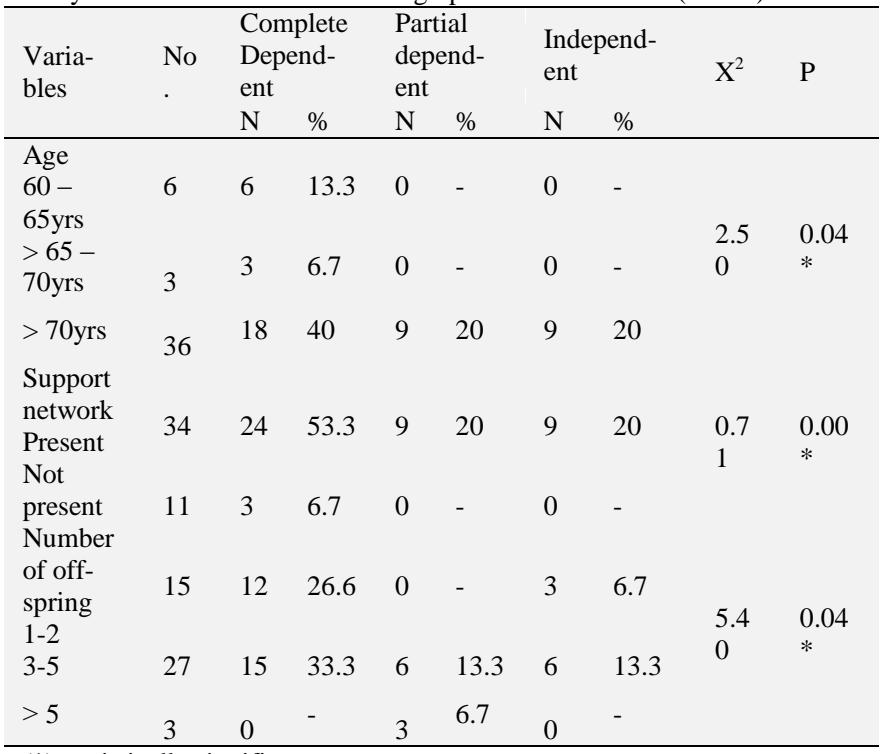

(*) statistically significant

Table 4: Correlation between Study Sample Older Adults' Cognitive Level and Their Socio Demographic Characteristics $(\mathrm{N}=45)$

\begin{tabular}{|c|c|c|c|c|c|c|c|c|c|}
\hline \multirow[b]{2}{*}{ Variables } & \multirow[b]{2}{*}{ No. } & \multicolumn{2}{|c|}{ Mild } & \multicolumn{2}{|c|}{ Moderate } & \multicolumn{2}{|c|}{ Severe } & \multirow[b]{2}{*}{$X^{2}$} & \multirow[b]{2}{*}{$\mathrm{P}$} \\
\hline & & $\mathrm{N}$ & $\%$ & $\mathrm{~N}$ & $\%$ & $\mathrm{~N}$ & $\%$ & & \\
\hline \multicolumn{10}{|l|}{ Age } \\
\hline $60-$ & 6 & 0 & 0 & 3 & 6.7 & 3 & 6.7 & \multirow{3}{*}{2.419} & \multirow{2}{*}{0.064} \\
\hline$>65-70$ & 3 & 0 & 0 & 3 & 6.7 & 0 & 0 & & \\
\hline$>70$ & 36 & 9 & 20 & 15 & 33.3 & 12 & 26.6 & & \\
\hline $\begin{array}{l}\text { Support } \\
\text { network }\end{array}$ & 34 & 6 & 13.3 & 21 & 46.6 & 15 & 33.3 & \multirow{3}{*}{3.275} & \multirow{3}{*}{0.076} \\
\hline Present & & & & & & & & & \\
\hline $\begin{array}{l}\text { Not pre- } \\
\text { sent }\end{array}$ & 11 & 3 & 6.7 & 0 & 0 & 0 & 0 & & \\
\hline $\begin{array}{l}\text { Number } \\
\text { of off- } \\
\text { spring }\end{array}$ & 15 & 6 & 13.3 & 3 & 6.7 & 6 & 13.3 & \multirow{4}{*}{5.469} & \multirow{4}{*}{0.084} \\
\hline $1-2$ & & & & & & & & & \\
\hline $3-5$ & 27 & 3 & 6.7 & 15 & 33.3 & 9 & 20 & & \\
\hline$>5$ & 3 & 0 & 0 & 3 & 6.7 & 0 & 0 & & \\
\hline
\end{tabular}

(*) statistically significant

Table 5: Relationship between Study Sample Older Adults' Cognitive Function Scale Domain Scores Before and After Applying Physical Exercise Program $(\mathrm{N}=45)$

\begin{tabular}{llllll}
\hline Items & $\begin{array}{l}\text { Pre-test } \\
\text { Mean } \pm \\
\text { SD }\end{array}$ & $\begin{array}{l}\text { Post-test } \\
(1) \text { Mean } \\
\pm \text { SD }\end{array}$ & $\begin{array}{l}\text { Post-test } \\
(2) \\
\text { Mean } \pm \\
\text { SD }\end{array}$ & F-test & $\begin{array}{l}\text { P- } \\
\text { value }\end{array}$ \\
\hline Orientation & $1.17+0.89$ & $1.67+0.55$ & $1.57+0.55$ & 1.52 & $0.04^{*}$ \\
Attention & $2.03+1.04$ & 2.40 & $2.20+0.94$ & 2.16 & $0.00^{*}$ \\
Memory & $1.26+0.98$ & $1.62+1.00$ & $1.41+1.01$ & 1.65 & $0.02^{*}$ \\
$\begin{array}{l}\text { Language } \\
\text { Visual-spatial } \\
\text { skills }\end{array}$ & $2.26+0.39$ & $2.35+0.38$ & $2.30+0.38$ & 1.38 & $0.01^{*}$ \\
\hline (*) statistically significant & $2.26+0.90$ & $2.67+0.86$ & $2.43+0.77$ & 0.39 & $0.05^{*}$ \\
\hline
\end{tabular}

*) statistically significant

Table 6: Relationship between Activity of Daily Living Scale Andcognitive Function Scale Scores Of Older Adults Before and After Applying the Structured Physical Exercise Program $(\mathrm{N}=45)$

\begin{tabular}{llllll}
\hline \multirow{2}{*}{ Items } & $\begin{array}{l}\text { Pre-test } \\
\text { Mean+SD }\end{array}$ & $\begin{array}{l}\text { Posttest (1) } \\
\text { Mean + SD }\end{array}$ & $\begin{array}{l}\text { Post-test (2) } \\
\text { mean + SD }\end{array}$ & F-test & P-value \\
\hline ADL & $1.73+0.62$ & $2.20+0.67$ & $1.90+0.77$ & 1.36 & $0.007^{*}$ \\
NOSCA & $1.53+0.58$ & $1.99+0.72$ & $1.97+0.55$ & 1.70 & $0.004^{*}$ \\
\hline
\end{tabular}

$(*)$ statistically significant

\section{Discussion}

It is believed that, the frailty of elderly patients is most often comprised of somatic, psychological and social problems simultaneously, which may result in problems in cognitive functioning, mood, behavior, activities of daily life, and thus quality of life (Langley 2000 \& Flaherty et al 2003). The determination of the individual's physical and cognitive status is important for; the choices of nursing interventions (Foreman, etal, 2003). The patient's both physical and cognitive abilities guide the nursing care considerably because they influence communication, support to be given in daily life activities, recognition and treatment of other nursing problems e.g. pain and behavioral problems (Milisen, etal 2006 \& Persoon et al 2009).

Literature strongly demonstrates evidence that, compared to less active men and women, older adults who are physically active have lower rates of life threatening physical, psychological or mental health problems. Exercise enhances mobility, flexibility, balance and posture in adults over 50 and improves flexibility, coordination, and reducing the risk of falls. As well, regular exercising is good for the brain functions and can help keep the brain active preventing memory loss, cognitive decline, and dementia. Exercise may even help slow the progression of brain disorders such as Alzheimer's disease (Spirduso 2007).

Based on that, planning and implementing structured physical exercises and exercise programs focusing on wellness and health promotion prepare older adults to be equipped to make wise health-related decisions in their life which guarantee their health and wellness. For that to be achieved, providing effective physical exercise programs at older adult geriatric homes can give them a chance to stay healthy for a longer periods in their lives (Guralnik 2006).

Findings of the current study will be discussed in terms of older adults ADL and cognitive functioning in relation to implementation of structured physical exercise program. The discussion will proceed to cover the following hypotheses; 1) Levels of performing daily living activities among older adults will be improved after the implementation of the structured physical exercise program, 2) Cognitive function of the older adults will be improved after the implementation of the structured physical exercise program.

The total sample consisted of forty five older adult females living in a charity geriatric home (Female section) in Giza Governorate. Their ages were 60 years and more; the majority of them aged more than 70 years. This result came synchronized with the recent Egypt population age distribution done in August 2014 which stated that, more than 5\% of population in Egypt aged 65 years and more, (Egypt Age structure 2014 www.indexmundi.com). This increase in the older adult's percentage in the Egyptian population may be due to the improvement in health care services rendered for them as well as the community wide attention given to this population sector.

Also findings of the current study revealed that, the majority of the study sample had support network. This result agree with Benevolent Society 2013(www.benevolent.org.au) who stated that, as older people are a significant population group and a growing section of the population comprising the majority of users of community care services, so they bring a diversity of experience to their family roles, responsibilities, and beliefs about health and disability. Based on that, they do need wide and strong support network to be more dependent and more involved.

Meanwhile, about two thirds of the study sample had a minimum of three and up to five offspring. These findings agree with (Gligoroska etal 2012), who found that, advanced age, having many children and lower education as well as lower socioeconomic standards have been independently associated with poorer functional and dependency status.

The current study found that, more than half of the study sample had a medical history of DM and forty percent had a medical history of hypertension. Meanwhile, more than half of the study sample had a main complaint of joint stiffness compared to nearly one 
eighth of the study sample had a main complaint of back pain. These results may be related to the unhealthy lifestyle followed by a large sector of the Egyptian population e.g. eating unhealthy and unbalanced diet and fast food, no or insufficient exercising, inadequate sleep and so on as well as poor use of community health services which in itself may be inadequate as compared to older adults' community needs. On the long run, all of these factors will inversely affect the older adults' health resulting in many physical illnesses as DM, hypertension, rheumatism, breast cancer ...etc. These findings come in harmony with Wisdom, Wiener et al (2010) who stated that, there is evidence that, women may be more liable to have multiple physical health impairments possibly due to their suffering from higher rates of non-fatal disabling condition such as, diabetes, hypertension and osteoarthritis.

Focusing on the study sample's ADL, statistically significant difference, indicating improvement, was found between levels of performing ADL among older adults of the study sample before and after implementing the structured physical exercise program. These results were expected as it is well known that, increasing the physical activity and regular exercising do help the individual, especially the older adult, to maintain active which intern enables $\mathrm{him} /$ her to carry out activities of daily livig more easily and effectively. Also, these results are consistent with (Bozo 2010) study who found that, regular physical activity is related to postponed disability and independent living in the oldest-old subjects. Even in individuals with chronic disease, systematic participation in physical activities enhances physical function.

The current study proved that, statistically significant difference, indicating improvement, was found between level of performing activities of daily living and the study sample's medical history data demonstrating improvements in performing activities of daily living for all the study sample regardless their medical diagnosis. These results were expected as it is a fact that, the more the individual keeps his / her body active, the more will be his / her competence and independence in carrying out activities of daily living. Also, these findings came in line with (Lautens et al 2008) who reported that, physical activity is related to physical function, and impaired function has predicted dependence and relative risk of admission to geriatric homes, particularly the functions of walking and ability to participate in outdoor activities.

The present study illustrated that, statistically significant differences, indicating improvement, were found between pre/post - test for ADL and NOSCA scales before and after implementing the structured physical exercise program. This result goes with (Lautenschlager \& Nicola 2008) who stated that, the more active is the older adult, the more will be his / her achievements and improvements of cognitive abilities.

As for, the impact of physical activity on cognition in older adults is more strongly supported by results from longitudinal studies, which generally show that, older adults who participated in physical activity show less cognitive decline over two- to 10- year follow-up periods with Regard to a variety of cognitive domains (working memory, processing speed, attention, and general mental functioning), (Barnes et al 2003). In the same line current study illustrated that, statistically significant differences, indicating improvement, were found between pre/post - test for cognitive function scale domains before and after implementing the structured physical exercise program.

Similarly this result is congruent with (Chaddock etal. 2011) who stated that, the aerobic exercise is potentially important not only for stopping the neuronal decline caused by aging process, but also is a potentially efficient mechanism for roll-back of some normal functions that have been disturbed due to reductions in brain structure related to aging.

This study showed no statistically significant difference was found between the study sample's cognitive level and neither their ages, presence of neither support network nor number of offspring. This may be due to the small sample number which allowed no detection of differences. This result contradicts (Perls, et al 2005 \& Kruk et al 2007) who stated that, decreased cognitive performance is significantly associated with the availability of older adult's surrounding support and central to this support is the presence of his / her offspring (if any).

\section{Conclusion}

Daily exercising and social activities positively affect older adults' physical and cognitive functioning resulting in higher level of independency.

Both Daily living activities (ADL) and Cognitive functions of study sample's older adults were declined before the implementation of the structured physical exercise program but they were significantly improved after implementing the program. So, the current study findings support the first and second hypotheses that are: (1) Levels of performing daily living activities among older adults will be improved after the implementation of the structured physical exercise program and (2) Cognitive function of the older adults will be improved after the implementation of the structured physical exercise program.

\section{Recommendations}

The current study recommended:

1) Wide range application of the developed structured physical exercise program on older adults in Egypt should be considered.

2) Developing educational programs as tools for improving the current knowledge, attitude and practice of older adults to improve their activity of daily living and cognitive functioning.

Replication of the current study on different settings and larger study samples would establish wider generalizability.

\section{References}

[1] American Psychological Association APA. (2013). Older adults' Health and Age-Related Changes, http://www.apa.org/pi/aging/resources/guides/older.aspx?item=2.

[2] APA. (2013). Changes in Mental Health and Mental Processes, http://www.apa.org/pi/aging/resources/guides/older.aspx?item=3.

[3] APA. (2013). Changes in Mental Health and Mental Processes, http://www.apa.org/pi/aging/resources/guides/older.aspx?item=6.

[4] Barnes D. E., Yaffe K., Satariano W. A., and Tager I. B. (2003). "A longitudinal study of cardiorespiratory fitness and cognitive function in healthy older adults," Journal of the American Geriatrics Society, vol. 51, no. 4, pp. 459-465, 2003. http://dx.doi.org/10.1046/j.1532-5415.2003.51153.x.

[5] Benevolent Society. (2013). (www.benevolent.org.au).

[6] Best Practice Information on Care Of Older adults. (2012). New York University, College of Nursing Issue Number 2, Revised. Hartford Institute Website www.hartfordign.org \& www.ConsultGeriRN.org.

[7] Bozo O, Guarnaccia CA. (2010): Activities of Daily Living, Social Support, and Future Health of Older Americans. The Journal of Psychology, 2010, 144(1), 1-14 http://dx.doi.org/10.1080/00223980903356032.

[8] Chaddock L, Pontifex M, Hillman CH, Kramer AF. (2011). A Review of the relation of Aerobic Activity to Brain Structure and Function in Children. J of Int Neuropsychol Society;17: 1-11. Doi. http://dx.doi.org/10.1017/S1355617711000567.

[9] Colcombe S J Erickson KI, Raz NI. (2003); Aerobic fitness reduces brain tissue loss in aging humans. J Gerontol A Biol Sci Med Sci. 58A: 176-180. Coded in The Effect of Physical Activity on Cognition - Physiological Mechanisms Mat Soc Med. 2012 Sep; 24(3): 198-20

[10] Egypt Age structure. (2014). www.indexmun-di.com/factbook> Countries $>$ Egypt $>$ Demographics. August 23

[11] Flaherty, E., Fulmer, T., \& Mezey, M. (2003). Geriatric Nursing Review Syllabus: a core curriculum in advanced practice geriatric nursing. New York: American Geriatrics Society.

[12] Foreman, M. D., Fletcher, K., Mion, L. C., \& Trygstad, L. (2003). Assessing cognitive function, Geriatric protocol for best practice, edited by M. Mezey, T. Fulmer, I. abraham, \& D. A. Zwicker, pp. 99-115. New York: Springer Publishing Company. 
[13] Gligoroska, Pluncevic, J. and Sanja Manchevska. (2012). "The Effect of Physical Activity on Cognition-Physiological Mechanisms." $\quad$ Materia $\quad$ socio-medica $24.3 \quad 198$. http://dx.doi.org/10.5455/msm.2012.24.198-202.

[14] Graf C.M.S. (2008). The Lawton Instrumental Activities of Daily Living Scale. AJN, American Journal of Nursing, 108 :(4), PP.52 - 62 http://dx.doi.org/10.1097/01.NAJ.0000314810.46029.74.

[15] Guralnik, j. M., e. M. Simonsick, 1. Ferrucci, L. (2006) A short physical performance battery assessing lower extremity function: association with self-reported disability and prediction of mortality and nursing home admission. J. Gerontol. Med. Sci. 49:M85-M94, http://dx.doi.org/10.1093/geronj/49.2.M85.

[16] Kamegaya, F. (2012). Pleasant Physical Exercise Program for Prevention of Cognitive Decline In Community-dwelling Elderly with Subjective Memory Complaints. Geriatric GerontolInt12 (4): PP.673-679.

[17] Kovatch S., Smith M., and Segal J., (2013). Maintaining of life style after 50 years of age; Exercise and Fitness retrieved from, http://www.helpguide.org/life/senior.

[18] Kovatch, S. M.F.A., and Segal, J. (2013). Exercise and Fitness over 50,http://www.helpguide.org/life/senior_fitness_sports.htm.

[19] Kruk B., and Joanna S., (2007). "Physical activity in the prevention of the most frequent chronic diseases: an analysis of the recent evidence." Asian Pacific Journal of Cancer Prevention 8.3 (2007): 325 .

[20] Langley, L. K. (2000). Cognitive assessment of older adults, assessing older persons: measures, meaning, and practical applications, edited by Kane RL \& R. Kane, pp. 65-128. New York: Oxford University Press.

[21] Lautenschlager D., \& Nicola T., (2008). "Effect of physical activity on cognitive function in older adults at risk for Alzheimer disease." JAMA: the journal of the American Medical Association 300.9 PP.1027-1037.

[22] Milisen, K., Braes, T., Fick, D. M., \& Foreman, M. D. (2006) Cognitive assessment and differentiating the 3 Ds (dementia, depression, delirium). Nurs. Clin. North Am. 41, 1-22, v. http://dx.doi.org/10.1016/j.cnur.2005.09.001.

[23] P Heyn, BC (2004). American Congress of Rehabilitation Medicine and the American Academy of physical medicine and rehabilitation, Elsevier.

[24] Perls, Thomas T., Morris JN, Ooi WL, Lipsitz LA "(2005).The relationship between age, gender and cognitive performance in the very old: the effect of selective survival." Journal of the American Geriatrics Society.

[25] Persoon (2011). Development of the nurses' Observation Scale for Cognitive Abilties ISRN Nursing.

[26] Persoon et al. (2012), Validation of the NOSCA - nurses' observation scale of cognitive abilities. Journal of Clinical Nursing, 21: 3025-3036. doi: 10.1111/j.1365-2702..04129. X.

[27] Persoon, A., Joosten.V, Weyn.D, Bannigh, L., Vrie, W., Rikkert, M. G. M. \& Achterberg, T. v. (2009). Daily observation of cognitive functioning in hospitalized patients on geriatric wars. J of Clinical Nursing,; 18, 1930-1936. http://dx.doi.org/10.1111/j.13652702.2009.02811.x

[28] Spirduso, Waneen W., and D. Leilani Cronin. (2007). "Exercise dose-response effects on quality of life and independent living in older adults. Medicine and Science in Sports and Exercise 33.6; SUPP S598-S608.

[29] Strength Training for older adults (2002). Centers for Disease Control and Prevention, Growing Stronger.http://www.cdc.gov/nccdphp/dnpa/physical/growing stronger.

[30] Suzuki et al. (2012). Effects of multicomponent exercise on cognitive function in older adults with amnestic mild cognitive impairment: a randomized controlled trial. BMC Neurology 12:128. http://dx.doi.org/10.1186/1471-2377-12-128.

[31] WHO May (2013). Physical Activity and Older Adult, http://www.who.int/dietphysicalactivity/factsheet_olderadults/en.

[32] Wiener, Joshua M., (2013). Measuring the activities of daily living: Comparisons across national surveys." Journal of Gerontology 45.6: PP.S229-S237.

[33] Wisdom, Marjorie. Mcgee, Horner-johnson, Yvonne. Michael, Adams, and Berlin. (2010). Health Disparities between Women with and Without Disabilities: A Review of the Research. Soc Work Public Health. May; 25(3): PP.368-386. doi: 10.1080/19371910903240969 http://dx.doi.org/10.1080/19371910903240969.

[34] Woodford H.J. and J. George, (2007). Cognitive assessment in the elderly. QJM: An International Journal of Medicine,, 100 :(8), PP. 469-484.
[35] World Health Organization WHO (2013). Health statistics and health information systems, http://www.who.int/healthinfo/survey/ageingdefnolder/en/. 